\title{
Prognostic value of high EZH2 expression in patients with different types of cancer: a systematic review with meta-analysis
}

\author{
Tao Jiang1, Yan Wang ${ }^{1}$, Fei Zhou ${ }^{1}$, Guanghui Gao', Shengxiang Ren ${ }^{1}$, Caicun Zhou ${ }^{1}$ \\ ${ }^{1}$ Department of Medical Oncology, Shanghai Pulmonary Hospital, Thoracic Cancer Institute, Tongji University School of \\ Medicine, Shanghai, 200433, P.R. China
}

Correspondence to: Caicun Zhou, e-mail: caicunzhou_dr@163.com

Keywords: enhancer of zeste homologue 2, cancer, prognosis, systematic review, meta-analysis

Received: September 11, 2015

Accepted: November 26, 2015

Published: December 14, 2015

\section{ABSTRACT}

Enhancer of zeste homologue 2 (EZH2) is a potential independent mechanism for epigenetic silencing of tumor suppressor genes in cancer. We conducted an electronic search on PubMed, EMBASE, Web of Science, and Cochrane library to perform this upto-date meta-analysis. Fifty-one studies with a total of 9444 patients were included. The prevalence of high EZH2 expression was 0.54 (95\% CI: 0.47-0.61). High EZH2 expression was significantly associated with poorer prognosis [overall survival: HR 1.54 (95\% CI: 1.30-1.78), P< 0.000; disease free survival: HR 1.35 (95\% CI: $1.00-$ 1.71), $P<0.000$ ]. In breast cancer, high EZH2 expression correlated with histological types [OR: 1.53 (95CI: 1.13-2.06); $P<0.006$ ], histological grade [OR: 1.62 (95CI: 1.35-1.95); $P<0.000$ ], estrogen receptor (ER) negativity [OR: 2.05 (95CI: 1.67-2.52); $P<0.000$ ], progesterone receptor $(P g R)$ negativity [OR: 1.42 (95CI: 1.03-1.96); $P=0.034$ ], HER-2 positivity [OR: 1.35 (95CI: 1.08-1.69); $P=0.009$ ], and high p53 expression [OR: 1.66 (95CI: 1.07-2.59); $P=0.024$ ]. These results suggest that high EZH2 expression may be a promising prognostic factor to different cancers. High EZH2 expression tends to correlate with pathological types, histological grade, ER negativity, PgR negativity, HER-2 positivity and p53 high expression in breast cancer.

\section{INTRODUCTION}

Enhancer of zeste homologue 2 (EZH2) is a catalytic subunit of the polycomb repressive complex 2 (PRC2), which represses gene expression by methylating lysine 27 of histone 3 (H3K27)[1]. EZH2-mediated methylation plays a pivotal role in epigenetic silencing of tumor suppressor genes in cancer and is involved in fundamental cellular processes, such as cell fate decision, cell cycle regulation, senescence and cell differentiation [2-6]. Hyperactivation of EZH2, either by high expression or mutations, is found in a variety of malignancies including breast, prostate, lung, gastric, and renal cell cancers in addition to glioblastoma[7-9].

EZH2 is highly expressed in a wide range of cancer types. In cell lines, enforced expression of EZH2 could increase proliferation and oncogenic capacity. Overexpressing EZH2 in mammary epithelial cells of the tumorigenic mouse model using mammary tumor virus long terminal repeat (MMTV-EZH2) leads to epithelial hyperplasia phenotype[10]. Previous studies have showed that high expression of EZH2 was correlated with aggressiveness, metastasis, and poor prognosis in breast, prostate, bladder and renal cell cancer[11-13]. Recently, some studies also demonstrated that high EZH2 expression was also associated with poor prognosis in lung and gastric cancer[14, 15], glioblatoma, head and neck squamous cell carcinoma[8, 16]. However, there are still quite a number of studies reported that there is no correlation between high EZH2 expression and prognosis in cancers mentioned above[17-19]. Moreover, some studies showed that high expression of EZH2 was the better prognostic factor in non-small-cell lung cancer (NSCLC) and colorectal cancer (CRC)[20, 21]. Although there have been already a metaanalysis on this issue, several important articles are not included in that paper and the subgroup analysis give little useful information[22]. Hence we performed this up-todate systematic review with meta-analysis on the influence of high EZH2 expression on the outcomes of different cancers, as well as the incidence of high EZH2 expression, 
and to provide an overview of the current status of high $\mathrm{EZH} 2$ expression in tumor progression and therapy.

\section{RESULTS}

\section{Study selection}

The result of literature inclusion was showed in Figure 1. A total of 1073 potentially relevant articles were found, and 51 studies were included in this analysis after screening[4, 6, 8, 11-21, 23-59]. Most of the excluded abstracts were reviews or studies with insufficient data.

\section{Characteristics of the studies}

In this analysis, 9444 cases from 51 studies were used to study high EZH2 expression in 18 kinds of human tumors. Sixteen of 51 studies were in breast cancer, 10 studies were in lung cancer, 7 studies were in CRC and other 21 studies were about digestive, gynecological and urinary cancers. The main characteristics of the included studies were shown in Table 1. In addition prognostic data were obtained from 16 of 54 studies on disease free survival (DFS) and 43 of 54 studies on overall survival (OS).

\section{Method of evaluation High EZH2 expression}

Quantitative reverse transcription-polymerase chain reaction (qRT-PCR) and immunohistochemistry
(IHC) staining were used to test high EZH2 expression. IHC was the most commonly used method (47 of 54) including 7 of them using both qRT-PCR and IHC. It is noteworthy that the criteria for high EZH2 expression were highly heterogeneous among different studies using IHC. For example, in some studies, the percentage of positive-staining tumor cells larger than 10\%, 25\%, 30\% or $50 \%$ were considered to be high EZH2 expression. In other studies, staining intensity $>50 \%$ was taken as high EZH2 expression. Immunoreactivity scores (IRS) was commonly used criterion, which were obtained for each case by multiplying the percentage and intensity score. The percentage scoring of immunoreactive tumor cells was as follows: $0(0 \%), 1(1-10 \%), 2$ (11-50\%) and $3(>50 \%)$. The staining intensity was visually scored and stratified as follows: 0 (negative), 1 (weak), 2 (moderate) and 3 (strong). However, in these studies used IRS, the cutoff values were different among different studies.

\section{Prevalence of high EZH2 expression}

The prevalence of high EZH2 expression in these studies ranged from $8.65 \%$ to $92.13 \%$, partly reflecting the heterogeneity in the criteria for high expression. In the meta-analysis of 51 studies, the prevalence of high EZH2 expression was 0.54 (95\% CI: 0.47-0.61) and large heterogeneity existed $\left(\mathrm{I}^{2}=98.4 \% ; P=0.000\right.$; Figure 2$)$. Subgroup analysis was stratified by test methods and
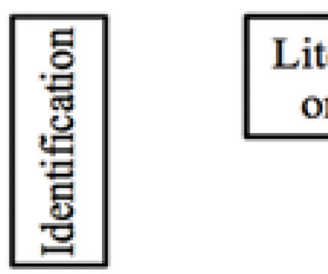

Literatures identified through online searching $(\mathrm{n}=1153)$

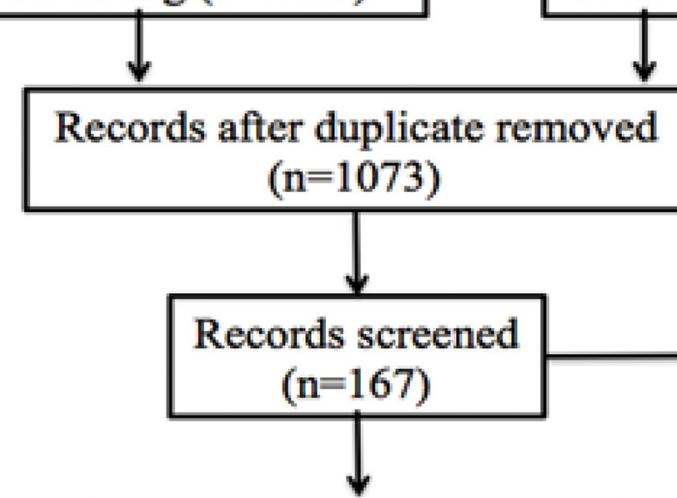

Additional records through other source searching $(n=4)$
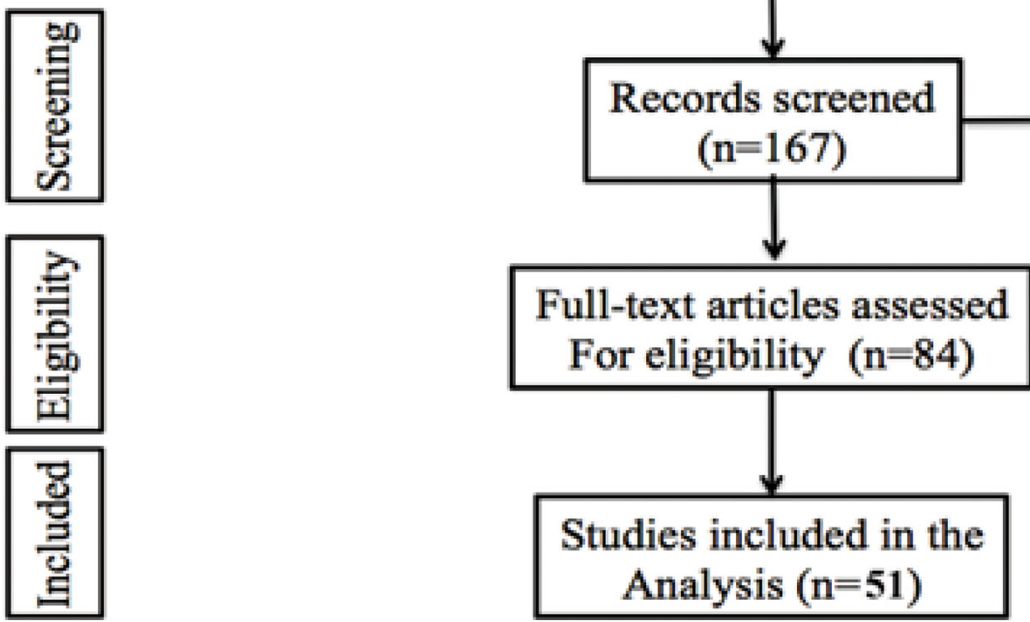

Full-text articles excluded for reasons $(\mathrm{n}=30)$

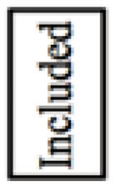

Figure 1: Flow diagram of the study selection process. 
Table 1: Characteristics of included studies

\begin{tabular}{|c|c|c|c|c|c|c|}
\hline $\begin{array}{l}\text { Cancer } \\
\text { Types }\end{array}$ & Author & Year & $\begin{array}{l}\text { Patients' } \\
\text { Number }\end{array}$ & $\begin{array}{c}\text { Rate of High } \\
\text { EZH2 Expression }\end{array}$ & Test Method & Definition of High Expression \\
\hline \multirow[t]{16}{*}{ Breast cancer } & Kleer & 2003 & 280 & $40.71 \%$ & $\mathrm{IHC}+\mathrm{qRT}-\mathrm{PCR}$ & $\begin{array}{l}\text { 3-4 score ( } 4 \text {-value intensity } \\
\text { score) defined high expression }\end{array}$ \\
\hline & Collett & 2006 & 190 & $47.37 \%$ & $\mathrm{IHC}$ & staining index (values $0-9$ ) $>3 *$ \\
\hline & Pietersen & 2008 & 295 & $40.34 \%$ & IHC & $\mathrm{NC}$ \\
\hline & Athanassiadou & 2011 & 100 & $64.00 \%$ & IHC & $>10 \%$ of nuclear staining \\
\hline & Gong & 2011 & 88 & $63.64 \%$ & $\mathrm{IHC}$ & $>10 \%$ of nuclear staining \\
\hline & Reijm & 2011 & 278 & $66.55 \%$ & IHC+qRT-PCR & $\mathrm{NC}$ \\
\hline & Alford & 2012 & 480 & $42.50 \%$ & IHC & $>25 \%$ of nuclei staining \\
\hline & Brot & 2012 & 140 & $85.71 \%$ & $\mathrm{IHC}$ & $>25 \%$ of nuclei staining \\
\hline & Hussein & 2012 & 261 & $33.33 \%$ & $\mathrm{IHC}$ & $\begin{array}{c}\text { nuclear staining was scored } \\
\text { based on intensity }(0-3) \text { and } \geq 2 \\
\text { defined high expression }\end{array}$ \\
\hline & Jene-Sanz & 2013 & 95 & $43.16 \%$ & IHC+qRT-PCR & $\mathrm{NC}$ \\
\hline & Knudsen & 2013 & 236 & $71.61 \%$ & $\mathrm{IHC}$ & $>15 \%$ of nuclear staining \\
\hline & Panousis & 2013 & 105 & $57.14 \%$ & IHC & $>10 \%$ of nuclei staining \\
\hline & Roh & 2013 & 49 & $67.35 \%$ & $\mathrm{IHC}$ & $>25 \%$ of nuclei staining \\
\hline & $\mathrm{Bae}$ & 2014 & 146 & $49.32 \%$ & $\mathrm{IHC}$ & $>30 \%$ of nucleai staining \\
\hline & Dong & 2014 & 410 & $24.15 \%$ & IHC & staining index (values $0-9$ ) $>3 *$ \\
\hline & Reijm & 2014 & 250 & $46.40 \%$ & IHC & 1 \\
\hline \multirow[t]{10}{*}{ Lung cancer } & Kikuchi & 2010 & 154 & $62.34 \%$ & $\mathrm{IHC}$ & $>25 \%$ of nuclei staining \\
\hline & Takawa & 2011 & 292 & $46.23 \%$ & IHC+qRT-PCR & $\mathrm{NC}$ \\
\hline & $\mathrm{Cao}$ & 2012 & 94 & $62.77 \%$ & RT-PCR & $\begin{array}{l}\text { A fold difference }>1 \text { is } \\
\text { considered high EZH2 } \\
\text { expression }\end{array}$ \\
\hline & Huqun & 2012 & 106 & $62.26 \%$ & $\mathrm{IHC}$ & $>50 \%$ of nuclei stained \\
\hline & Lv & 2012 & 69 & $63.77 \%$ & IHC+qRT-PCR & $>25 \%$ of nuclei staining \\
\hline & Behrens & 2013 & 541 & $26.80 \%$ & IHC & $\begin{array}{l}\text { final score (values } 0-300 \text { ) } \\
\qquad>125^{* *}\end{array}$ \\
\hline & Chen & 2013 & 42 & $42.86 \%$ & IHC & $\begin{array}{l}\text { final IHC score (values } 0-12 \text { ) } \\
\qquad>3 * *\end{array}$ \\
\hline & Wan & 2013 & 113 & $50.44 \%$ & $\mathrm{IHC}$ & $\mathrm{NC}$ \\
\hline & $\mathrm{Xu}$ & 2014 & 360 & $56.67 \%$ & IHC & staining index (values $0-9$ ) $>3 *$ \\
\hline & Geng & 2015 & 195 & $49.23 \%$ & IHC & $\begin{array}{l}\geq 30 \% \text { of tumor cells with } \\
\text { strong staining intensity=2 }\end{array}$ \\
\hline \multirow[t]{4}{*}{$\begin{array}{l}\text { Colorectal } \\
\text { cancer }\end{array}$} & Mimori & 2005 & 61 & $52.46 \%$ & qRT-PCR & $\begin{array}{l}>\text { the median tumor/normal } \\
\text { ratio }\end{array}$ \\
\hline & Fluge & 2009 & 241 & $17.01 \%$ & $\mathrm{IHC}$ & staining index (values $0-9$ ) $>3 *$ \\
\hline & Wang & 2010 & 119 & $69.75 \%$ & $\mathrm{IHC}$ & $>30 \%$ of nucleai staining \\
\hline & Takawa & 2011 & 172 & $91.86 \%$ & IHC & $\mathrm{NC}$ \\
\hline
\end{tabular}

(Continued) 


\begin{tabular}{|c|c|c|c|c|c|c|}
\hline $\begin{array}{l}\text { Cancer } \\
\text { Types }\end{array}$ & Author & Year & $\begin{array}{l}\text { Patients' } \\
\text { Number }\end{array}$ & $\begin{array}{c}\text { Rate of High } \\
\text { EZH2 Expression }\end{array}$ & Test Method & Definition of High Expression \\
\hline & Benard & 2014 & 247 & $23.89 \%$ & IHC+qRT-PCR & $\begin{array}{c}>\text { median percentage of } \\
\text { positively stained nuclei in the } \\
\text { marked area }\end{array}$ \\
\hline & Meng & 2014 & 112 & $52.68 \%$ & $\mathrm{IHC}$ & $>50 \%$ of nucleai staining \\
\hline & Liu & 2015 & 82 & $80.49 \%$ & qRT-PCR & $\begin{array}{c}>\text { the median tumour/normal } \\
\text { ratio }\end{array}$ \\
\hline \multirow[t]{2}{*}{$\begin{array}{l}\text { Bladder } \\
\text { cancer }\end{array}$} & Raman & 2005 & 24 & $87.50 \%$ & IHC & staining index (values $0-9$ ) $>3 *$ \\
\hline & Hinz & 2008 & 99 & $90.91 \%$ & qRT-PCR & $>$ median expression levels \\
\hline \multirow[t]{2}{*}{$\begin{array}{l}\text { Prostate } \\
\text { cancer }\end{array}$} & Bachmann & 2006 & 104 & $8.65 \%$ & $\mathrm{IHC}$ & staining index (values $0-9$ ) $>3 *$ \\
\hline & $\mathrm{Li}$ & 2011 & 129 & $44.96 \%$ & $\mathrm{IHC}$ & staining index (values $0-9$ ) $>3 *$ \\
\hline \multirow[t]{3}{*}{ Renal cancer } & Hinz & 2013 & 101 & $56.44 \%$ & IHC+qRT-PCR & $>$ median expression levels \\
\hline & Wagener & 2009 & 411 & $11.19 \%$ & $\mathrm{IHC}$ & $>25 \%$ of nucleai staining \\
\hline & Liu & 2010 & 373 & $52.82 \%$ & $\mathrm{IHC}$ & $\begin{array}{l}\text { final IHC score (values } 0-12 \text { ) } \\
\geq 2^{* * *}\end{array}$ \\
\hline \multirow[t]{2}{*}{ Glioblastoma } & $\mathrm{Wu}$ & 2013 & 128 & $62.50 \%$ & $\mathrm{IHC}$ & $\begin{array}{l}\text { staining index (values } 0-9 \text { ) } \\
>4.5^{*}\end{array}$ \\
\hline & Zhang & 2013 & 83 & $51.81 \%$ & $\mathrm{IHC}$ & $\begin{array}{l}\geq 2 \text { (scored } 0 \text { to } 3 \text { ) indicated } \\
\text { high expression }\end{array}$ \\
\hline \multirow[t]{7}{*}{$\begin{array}{l}\text { Digestive } \\
\text { cancer }\end{array}$} & $\mathrm{He}$ & 2015 & 98 & $54.08 \%$ & IHC & $>50 \%$ of nucleai staining \\
\hline & Liu & 2010 & 108 & $53.70 \%$ & $\mathrm{IHC}$ & $>25 \%$ of nuclei staining \\
\hline & $\mathrm{Ha}$ & 2011 & 164 & $52.44 \%$ & $\mathrm{IHC}$ & $\begin{array}{l}\text { final IHC score (values } 0-12 \text { ) } \\
\geq 10^{* * *}\end{array}$ \\
\hline & $\mathrm{He}$ & 2012 & 117 & $70.09 \%$ & $\mathrm{IHC}$ & $>50 \%$ of nucleai staining \\
\hline & Lee & 2012 & 178 & $92.13 \%$ & IHC & $\begin{array}{c}\text { staining index (values 0-9) } \\
\text { >median score* }\end{array}$ \\
\hline & $\mathrm{Li}$ & 2012 & 84 & $64.29 \%$ & IHC & $\begin{array}{l}\text { final IHC score (values } 0-12 \text { ) } \\
\geq 4^{* * *}\end{array}$ \\
\hline & Zhang & 2013 & 167 & $76.05 \%$ & IHC & staining index (values $0-9$ ) $>3 *$ \\
\hline \multirow[t]{3}{*}{$\begin{array}{l}\text { Gynecological } \\
\text { cancer }\end{array}$} & Bachmann & 2006 & 276 & $17.75 \%$ & IHC & staining index (values $0-9$ ) $>3 *$ \\
\hline & Rao & 2010 & 179 & $49.72 \%$ & IHC & $>50 \%$ of nucleai staining \\
\hline & Liu & 2014 & 101 & $68.32 \%$ & IHC & staining index (values $0-9$ ) $\geq 4 *$ \\
\hline $\begin{array}{l}\text { Head and } \\
\text { neck cancer }\end{array}$ & Cao & 2014 & 117 & $50.43 \%$ & $\mathrm{IHC}$ & $\begin{array}{l}\text { cutoff value was set as the } \\
\text { median of the labeling index }\end{array}$ \\
\hline
\end{tabular}

*: staining index (values 0-9) $=$ staining intensity $(0-3) \times$ proportion of immunopositive cells $(<10 \%=1,10-50 \%=2$, $>50 \%=3)$.

**: The final score was then obtained by multiplying the inten- sity and extension values (range, $0-300$ ) by using a 4-value intensity score $(0,1,2$, and 3$)$ and the percentage $(0-100 \%)$ of the extent of reactivity in each core.

***: the number of positive cancerous cells was estimated as follows ( 0 , no positive cells; $1,0-25 \%$ positive cells; 2 , $25-50 \%$ positive cells; $3,50-75 \%$ positive cells; and $4,75-100 \%$ positive cells). These scores were multiplied with an intensity scale ( 0 , negative; 1 , weak; 2 , moderate; and 3, intensive), and the final score ranged from 0-12; NC: not clear. 
evaluation criteria, but the heterogeneity could not be reduced (Supplementary Figures S1-S2). In subgroup analysis, the rates of high EZH2 expression in breast cancer, lung cancer and CRC were 0.53 (95\%CI: 0.44 $0.62), 0.52$ (95\%CI: $0.42-0.62)$ and 0.55 (95\%CI: 0.29 $0.82)$, respectively.

\section{Meta-analysis of high EZH2 expression and cancer prognosis}

Pooled OS was used to illustrate high EZH2 expression overall effect for the studies containing prognostic data. Meta-analysis of high EZH2 expression status and

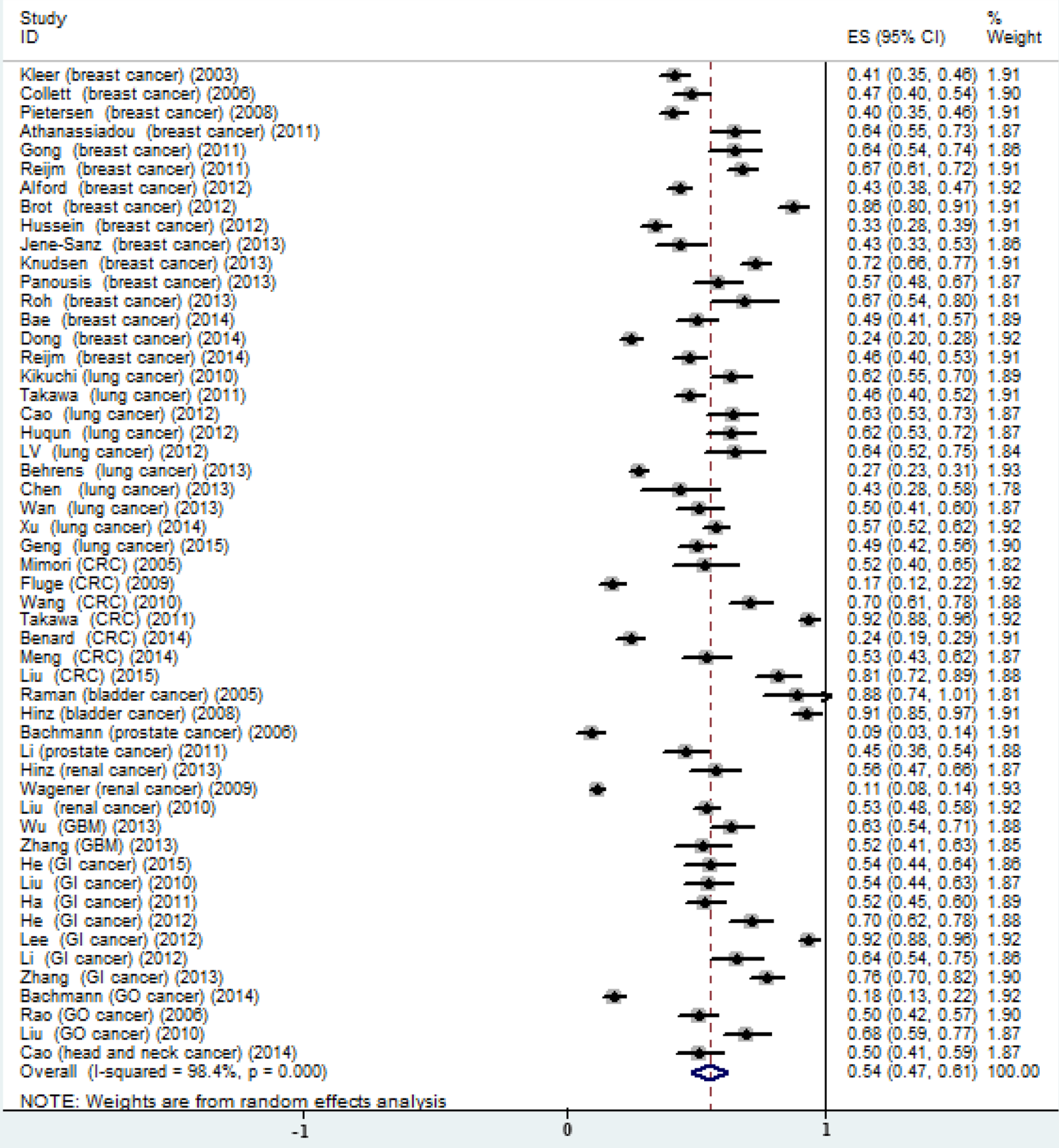

Figure 2: Meta-analysis of the prevalence of EZH2 high expression in all included studies. 


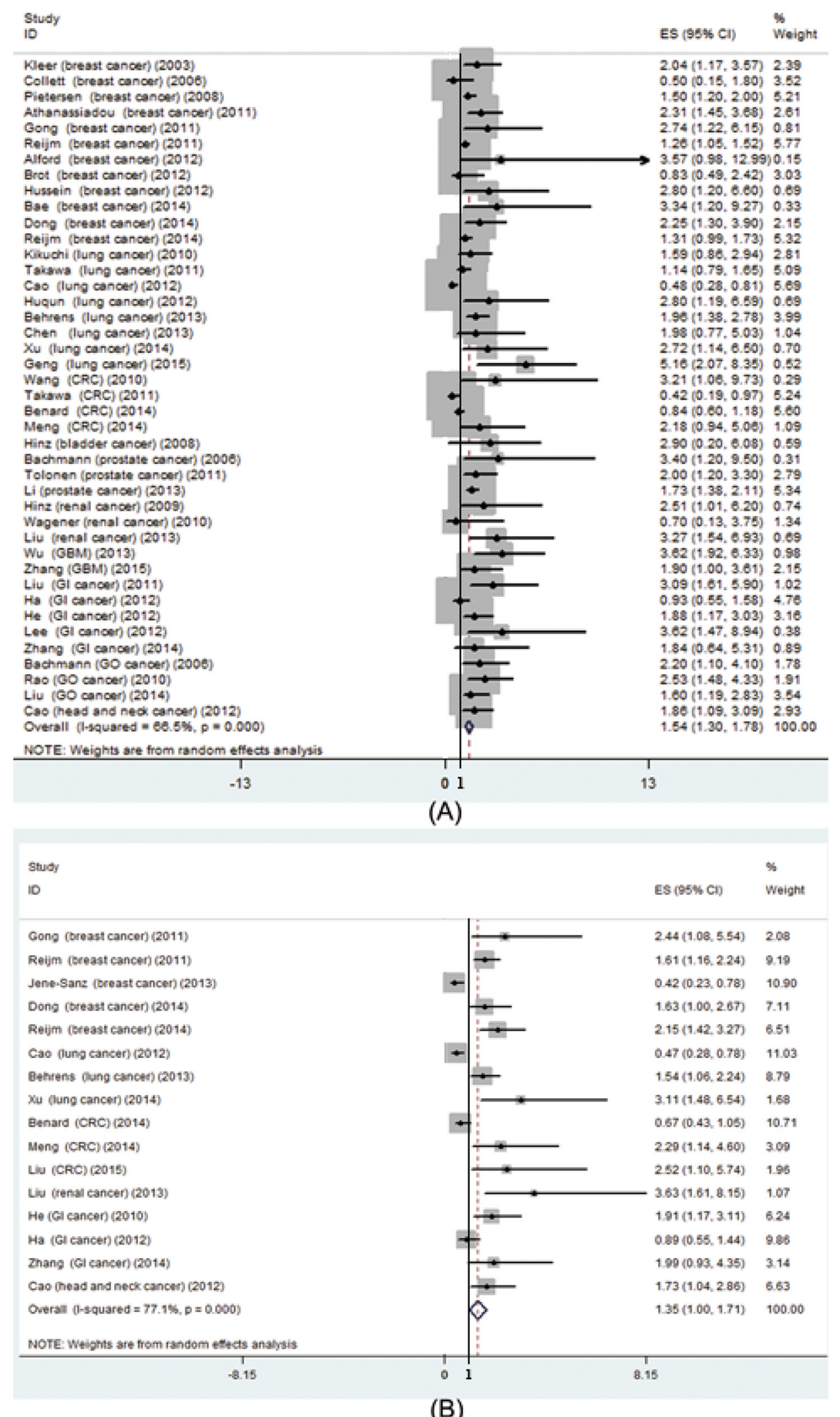

(B)

Figure 3: Prognostic value of EZH2 high expression in patients with cancer. A. meta-analysis of EZH2 high expression and overall survival in various cancers; B. meta-analysis of EZH2 high expression and disease free survival in various cancers. 
OS in a variety of cancers was performed; 8252 patients in 43 studies for high EZH2 expression were included. The results showed that the pooled HRs were significant for high EZH2 expression [HR 1.54 (95\% CI: 1.30-1.78); $P=0.000$ ] (Figure 3A). Pooled HRs $>1$ indicated that high EZH2 expression would be correlated with poor OS in various cancers. However, the results showed high heterogeneity $\left(\mathrm{I}^{2}=66.5 \% ; P=0.000\right)$. In the sixteen studies that reported DFS, the pooled result indicated that high EZH2 expression was also related to shorter DFS [HR: 1.35 (95\% CI: 1.0$1.71) ; P=0.000$; Figure $3 \mathrm{~B}]$. The results also showed high heterogeneity $\left(\mathrm{I}^{2}=77.1 \% ; P=0.000\right)$.

In addition we carried out the meta-analysis of high EZH2 expression and prognosis in breast, lung and colorectal cancer, respectively. The results showed that high EZH2 expression was correlated with poor OS [HR: 1.40 (95\% CI: 1.13-1.67); $P=0.000$; Figure $4 \mathrm{~A}]$ in breast cancer instead of lung [HR: $1.60(95 \%$

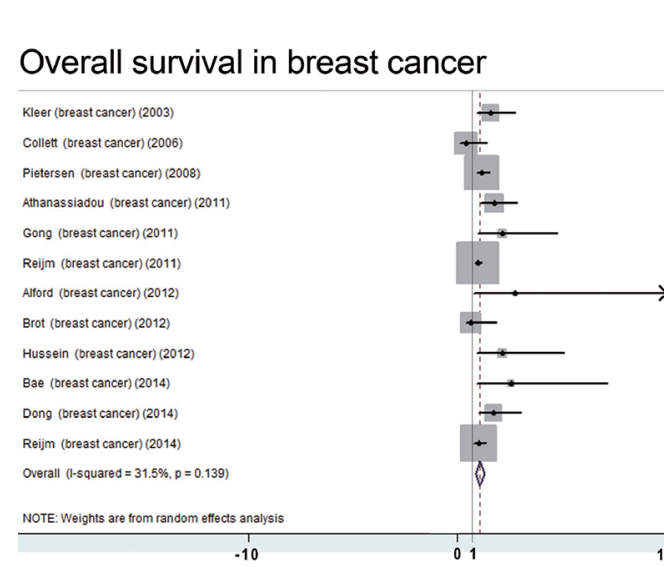

(A)

Overall survival in colorectal cancer
ES (95\% Cl) $\quad \%$

$2.04(1.17 .3 .57) \quad 4.40$ $0.50(0.15,1.80) \quad 8.19$ $1.50(1.20,2.00) \quad 19.99$ $2.31(1.45,3.68) \quad 5.01$ $2.74(1.22,6.15) \quad 1.15$ $1.26(1.05,1.52) \quad 28.16$ $3.57(0.98,12.99) \quad 0.20$ $0.83(0.49,2.42) \quad 6.34$ $2.80(1.20,6.60) \quad 0.96$ $3.34(1.20,9.27) \quad 0.44$ $2.25(1.30,3.90) \quad 3.80$ $1.31(0.99,1.73) \quad 21.36$ $1.40(1.13,1.67) \quad 100.00$

10

9
6
0

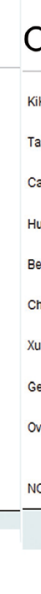

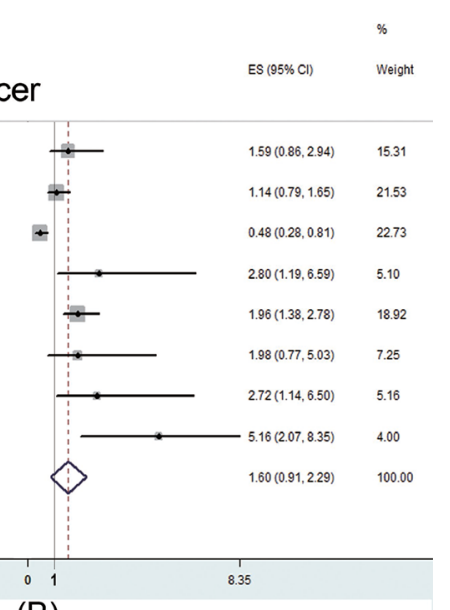

(B)

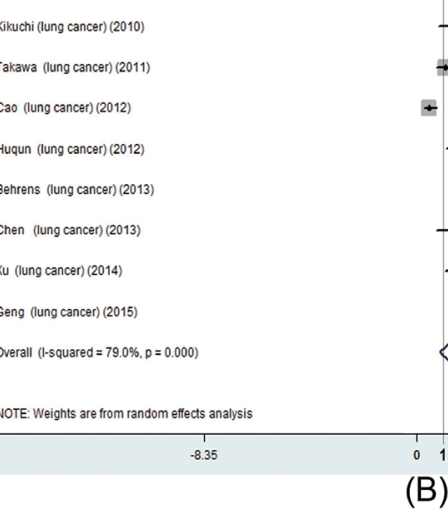

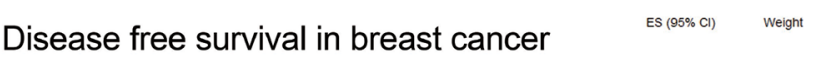
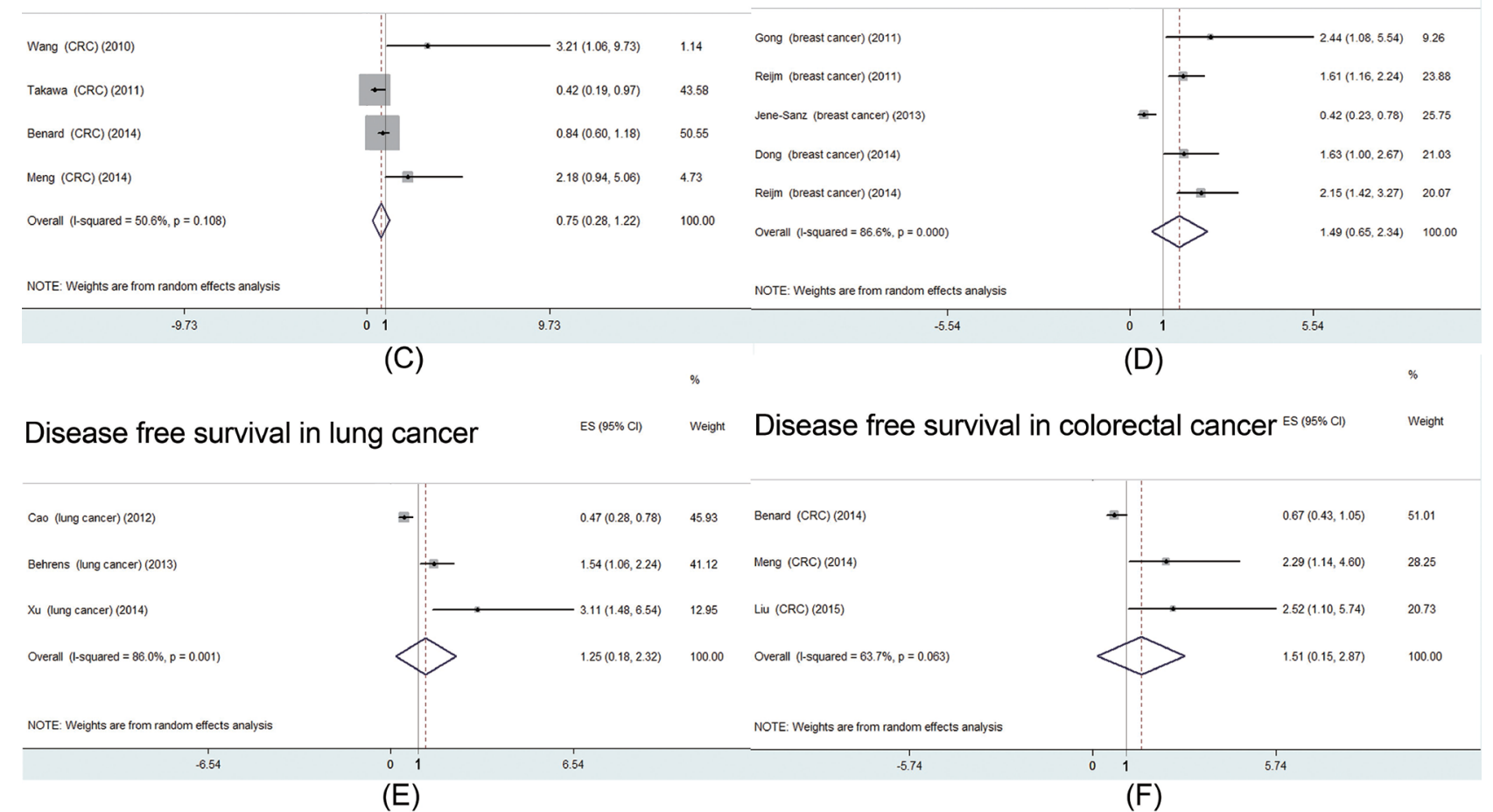

Figure 4: Prognostic value of EZH2 high expression in patients with breast, lung or colorectal cancer. A. meta-analysis of EZH2 high expression and overall survival in patients with breast cancer; B. meta-analysis of EZH2 high expression and overall survival in patients with lung cancer; C. meta-analysis of EZH2 high expression and overall survival in patients with colorectal cancer; D. metaanalysis of EZH2 high expression and disease free survival in patients with breast cancer; E. meta-analysis of EZH2 high expression and disease free survival in patients with lung cancer; F. meta-analysis of EZH2 high expression and disease free survival in patients with colorectal cancer; 
CI: 0.91-2.29); $P=0.376$; Figure 4B] and CRC [HR: 0.75 (95\% CI: 0.28-1.22); $P=0.340$; Figure 4C]. All three pooled results indicated that high EZH2 expression was not related to shorter or longer DFS, respectively (Figure 4D-4F).

\section{High EZH2 expression and clinicopathological features}

To explore the relationship between high EZH2 expression and clinicopathological parameters, subgroup analyses were performed according to the different cancer types. The details were summarized in Table 2. As the results suggested, in breast cancer, high EZH2 expression was associated with pathological types [OR: 1.53 (95CI: 1.13-2.06); $P=0.006$ ], histological grade [OR: 1.62 (95CI: $1.35-1.95) ; P=0.000]$, estrogen receptor (ER) negativity [OR: 2.05 (95CI: 1.67-2.52); $P=0.000$ ], progesterone receptor (PgR) negativity [OR: 1.42 (95CI: 1.03-1.96); $P$ $=0.034$ ], HER-2 positivity [OR: 1.35 (95CI: 1.08-1.69); $P=0.009$ ], and p53 high expression [OR: 1.66 (95CI: 1.07-2.59); $P=0.024]$. In $\mathrm{CRC}$ and lung cancer, high EZH2 expression was not correlated with the reported clinicopathological features (Table 2).

\section{Sensitivity and publication bias}

Analysis of sensitivity was performed by omitting one study at one time to measure its effect on prevalence and pooled HRs. Deletion of the study by Li et al. [56] significantly reduced the heterogeneity in the analysis of high EZH2 expression and OS. No other individual study influenced the results. Begg's funnel plots and Egger's tests evaluated the publication bias, and it was only detected in the analysis of high EZH2 expression prevalence $(P=0.021$ for Egger's test). In the other analyses, the Begg's funnel plots were almost symmetric (Figure 5) and Egger's tests indicated that there was no evidence of publication bias.

\section{DISCUSSION}

In this article, the results indicated that $\mathrm{EZH} 2$ highly expressed in 18 kinds of human cancers and the incidence of high EZH2 expression was 0.54 (95\% CI: 0.47-0.61). More importantly, the results of all included studies demonstrated that high expression of EZH2 could be the prognostic factor for both OS and DFS [HR: 1.54 (95\% CI: 1.30-1.78), HR: 1.35 (95\% CI: 1.0-1.71); $p=$ 0.000 ; respectively]. In virtue of the high heterogeneity, we performed the subgroup analysis on breast, lung and colorectal cancer. The results showed that high EZH2 expression was associated with poor OS in breast cancer instead of lung and CRC. All three pooled results indicated that high EZH2 expression was not related to shorter or longer DFS. In breast cancer, EZH2 inhibited the tumor suppressor RKIP transcription through repression-associated histone modifications, therefore promoting tumor progression and metastasis [5]. This may partly explain the reason why high EZH2 expression was correlated with poor OS in breast cancer. As to the clinicopathological parameters, we found that high EZH2 expression was associated with ER negativity, PgR negativity, HER-2 positivity and p53 high expression. These results are concordant with previous study. In addition, we also found an association between high EZH2 expression and histological grade. This would also be part of reason that high EZH2 expression was correlated with poor OS in breast cancer.

Another important issue is the assessment of high EZH2 expression. To date, there is no golden standard for scoring EZH2 expression. Our study collected all test methods and scoring system from the included studies (Table 1). The method reported by Bachmann et al.[12] was widely used (10 studies). They defined EZH2 positive expression via the product of intensity and quantity (cutoff value $>3$ ). However, other studies used different criteria including 3 studies used the nuclear immunostaining $>10 \%, 7$ studies used $>25 \%, 3$ studies used $>30 \%, 5$ studies used $>50 \%$ and 4 studies used the final IHC score $\geq 4$. This would be the major reason on high heterogeneity of high EZH2 expression rate. Recently, the researcher used a sum of intensity and quantity with a cutoff value of $>2$ to quantify tumors as high EZH2 expression and obtained a similar association between EZH2 protein expression and progress free survival (PFS)[35]. Thus, the relation seems to be independent of the method of scoring, as long as the amount proportion of stained cells is included since intensity by itself did not associate with PFS, whereas quantity did according to different methods.

Accumulated evidence indicates that EZH2 contributes to various aspects of cancer by regulating a variety of target genes. It was shown that EZH2containing PRC2 transcriptionally inhibited cell cycle suppressor INK-ARF to drive cell cycle progression, prevent cell senescence and also exhaustion of cancer stem cells. In addition, EZH2 promotes epithelial-mesenchymal transition (EMT), a process that is associated with cancer progression and metastasis, by interacting with transcription factor SNAIL1 and suppressing expression of epithelial marker E-cadherin (CDH1). Moreover, EZH2 is implicated in promoting tumor angiogenesis. It shows that vascular endothelial growth factor (VEGF), which stimulates angiogenesis, can increase E2F1/3 transcription factors to transactivate EZH2 expression. Increased EZH2 expression by VEGF silences expression of a negative regulator of angiogenesis, vasohibin1 (VASH1), and subsequently enhances angiogenesis. Another recent study further identified that under hypoxia insult, induced EZH2 expression decreases DNA damage repair protein RAD51 
Table 2: The association between clinicopathological parameters and EZH2 high expression with respect to patients with different cancers

\begin{tabular}{|c|c|c|c|c|c|}
\hline \multirow[t]{2}{*}{ Factors } & \multirow[t]{2}{*}{ No. of study } & \multirow[t]{2}{*}{ OR $(95 \% C I)$} & \multirow[t]{2}{*}{ p value } & \multicolumn{2}{|c|}{ Heterogeneity } \\
\hline & & & & I2 & p value \\
\hline \multicolumn{6}{|l|}{ Breast Cancer } \\
\hline Age $>65 /<65$ & 4 & $0.917(0.721-1.167)$ & 0.483 & $0.0 \%$ & 0.586 \\
\hline Ethnicity (Asian/Caucasian) & 16 & $1.133(0.632-2.030)$ & 0.762 & $76.6 \%$ & 0.039 \\
\hline Histology (ductal/other) & 7 & $1.526(1.130-2.062)$ & 0.006 & $0.0 \%$ & 0.773 \\
\hline Histological grade (III/I-II) & 9 & $1.620(1.349-1.947)$ & 0.000 & $46.8 \%$ & 0.059 \\
\hline Lymph node status $(\mathrm{P} / \mathrm{N})$ & 9 & $1.106(0.876-1.397)$ & 0.397 & $32.3 \%$ & 0.160 \\
\hline ER status (N/P) & 8 & $2.053(1.673-2.521)$ & 0.000 & $3.10 \%$ & 0.406 \\
\hline PR status (N/P) & 8 & $1.420(1.027-1.962)$ & 0.034 & $54.8 \%$ & 0.030 \\
\hline $\operatorname{HER}-2(\mathrm{P} / \mathrm{N})$ & 10 & $1.348(1.078-1.685)$ & 0.009 & $0.0 \%$ & 0.792 \\
\hline p53 (H/L) & 4 & $1.664(1.069-2.588)$ & 0.024 & $35.5 \%$ & 0.199 \\
\hline \multicolumn{6}{|l|}{ Lung Cancer } \\
\hline Age $(>65 /<65)$ & 5 & $1.014(0.817-1.258)$ & 0.901 & $0.0 \%$ & 0.941 \\
\hline Gender (male/female) & 7 & $1.041(0.768-1.412)$ & 0.793 & $52.5 \%$ & 0.049 \\
\hline Ethnicity (Asian/Caucasian) & 10 & $1.523(0.932-2.474)$ & 0.313 & $50.4 \%$ & 0.049 \\
\hline Smoking (non/smoker) & 5 & $0.940(0.551-1.663)$ & 0.831 & $75.4 \%$ & 0.003 \\
\hline Histology (Ade/other) & 5 & $1.099(0.639-1.890)$ & 0.733 & $78.2 \%$ & 0.001 \\
\hline Differentiation (well/poor) & 6 & $0.749(0.445-1.260)$ & 0.276 & $66.7 \%$ & 0.010 \\
\hline Lymph node (N/P) & 3 & $0.816(0.411-1.620)$ & 0.561 & $86.4 \%$ & 0.001 \\
\hline Stage (I/II-IV) & 4 & $0.888(0.563-1.402)$ & 0.611 & $52.9 \%$ & 0.095 \\
\hline \multicolumn{6}{|l|}{ Colorectal Cancer } \\
\hline Gender (male/female) & 3 & $0.970(0.715-1.316)$ & 0.845 & $0.0 \%$ & 0.767 \\
\hline Differentiation (well/poor) & 3 & $0.806(0.515-1.262)$ & 0.348 & $0.0 \%$ & 0.690 \\
\hline Lymph node (N/P) & 4 & $0.890(0.666-1.189)$ & 0.432 & $0.0 \%$ & 0.622 \\
\hline
\end{tabular}

Abbreviations: No.: number; OR: odds ratio; CI: confidence interval; Ade: adenocarcinoma; P: positive; N: negative; H: high expression; L: low expression

expression, which leads to genomic aberrations, such as RAF1 gene amplification, to promote RAF1-ERK- $\beta$ catenin signaling and expansion of breast tumor initiating cells. Taken together, EZH2 plays an essential and multifaceted role in human cancers. Blocking EZH2 expression or activity may represent a promising strategy for anticancer treatment targeting tumor cells, tumor endothelial cells and tumor stem cells.

To date, several potent inhibitors of $\mathrm{EZH} 2$ have been discovered. One of the most valuable inhibitors is 3-deazaneplanocin A (DZNep). DZNep is a $S$ adenosylhomocysteine hydrolase inhibitor. It can deplete EZH2 and the associated H3K27me3 and induce apoptosis in breast and colon cancer cells[60]. More importantly, at the animal level, DZNep could affect the epigenetic pathway with minimal toxicity. Similarly, DZNep was shown to be effective in inhibiting prostate cancer cell growth and its anti-tumor activity is in part mediated by suppressing the tumorigenic potential of the prostate cancer stem cell[61]. However, all of the reported inhibitors were just confirmed effective in cell lines and/ or mice based experiments. The therapeutic value of these inhibitors needs to be further assessed.

When interpreted the results, some limitations of our meta-analysis should be acknowledged. Firstly, it is possible that there may be some degree of publication bias in this area of research. We identified several abstracts describing articles that were not further detailed in 
standard publications. We have made any effort to contact authors of primary studies. However, we have not received any reply. Hence, we could not include these articles in the review. Secondly, there was statistical heterogeneity among the studies regarding the prevalence of high EZH2 expression. Studies may have differed with regard to the baseline characteristics of the patients included age, histological type, differentiation, disease stage, the duration of follow-up and adjustments for other cofactors. Fortunately, we found that the heterogeneity may be due to the lack of test method and evaluation criteria. Thirdly, there is clearly a multitude of confounding factors (laboratory condition, test technique and so on) that make experiment comparisons difficult.

In conclusion, the current evidence suggests that high EZH2 expression may be a promising prognostic factor to human cancers, especially the breast cancer. High expression of EZH2 trends to correlate with histological grade, ER negativity, PgR negativity, HER-2 positivity and p53 high expression. EZH2 is an attractive target in future cancer treatment. In addition, some questions should be illustrated clearly, including the test method and evaluation criteria of high EZH2 expression before large scale clinical studies being conducted.

\section{METHODS}

\section{Publication search strategy}

We performed a comprehensive publication search through the PubMed, EMBASE, Web of Science, and Cochrane library up to March 31, 2015, without language limitations. The following contextual query language was used: ("Enhancer of Zeste Homologue 2" OR "EZH2”) AND ("cancer" OR "carcinoma" OR "neoplasm"). Titles and abstracts were reviewed to identify reports, which examined the association of EZH2 expression with clinical outcomes, such as overall survival (OS), disease free survival (DFS) and clinicopathological features. Reference lists of identified studies and reviews were also handsearched. We have made any effort to contact authors of primary studies. This analysis was performed in

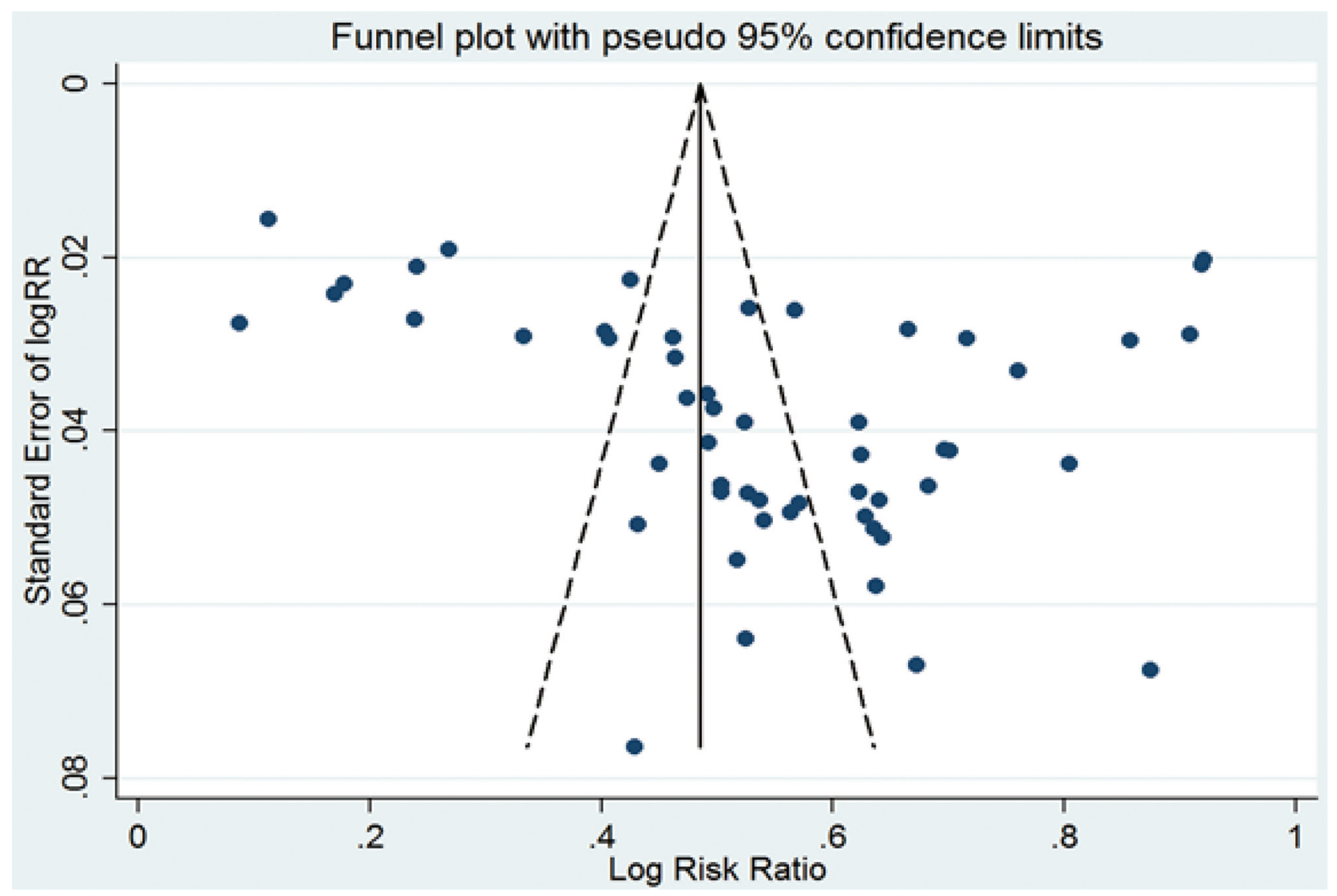

Figure 5: Publication bias for the prevalence of EZH2 high expression in various cancers. 
accordance with Preferred Reporting Items for Systematic Reviews and Meta-Analyses: the PRISMA Statement[62].

\section{Study selection}

The criteria for inclusion were listed as follows: (1) studied high EZH2 expression in any type of human cancers; (2) the expression of EZH2 was detected on tumor tissue, rather than in the serum or cell lines or any other kinds of specimens; and (3) reported data necessary to calculate the incidence of high EZH2 expression and/ or high risk (HR) on survival outcomes. Studies were excluded if they were: (1) reviews, case-only studies, or familial studies; (2) lacking sufficient data for calculation of incidence and/or HR with $95 \%$ confidence intervals (CIs); and (3) duplication of previous publications or replicated samples. Two reviewers determined study eligibility independently. Disagreements were solved by consensus.

\section{Data extraction}

From each study, the following information was extracted: first author's name, year of publication, study population, EZH2 expression assessment methods, cut-off definition, and incidence of high EZH2 expression with 95\% CIs, HR for OS, and/or DFS with corresponding 95\% CIs. If the HRs and CIs were not reported, the total observed death events and the numbers of patients in each group were extracted to calculate HR and its variance indirectly. In order to guarantee the accuracy of collected data, studies for which only Kaplan-Meier curves would not be included. When both univariate analysis and multivariate analysis were reported to get the HR, the results of multivariate analysis were selected. Two reviewers extracted the data independently, using a predefined Excel form. Disagreements were resolved by consensus after discussion. If they can't get the consensus, the article would be excluded.

\section{Quality assessment}

Two reviewers assessed the study quality independently by using the following factors: (1) distinct definition of the study population and the type of cancer; (2) clear definition of the test method and the cut-off value of high EZH2 expression; (3) sample size larger than ten and (4) clear definition of the outcome assessment (if applicable). Studies lacking any of these criteria were excluded.

\section{Statistical analysis}

For the incidence of high EZH2 expression, the incidences and 95\% CIs were combined. Dichotomous data were compared using an odds ratio (OR). Respective 95\% CIs were calculated for each estimate and presented in forest plots. For time-to-event data, the HRs with their $95 \%$ CIs were directly extracted from the research article or calculated using previously published methods proposed by Tierney et al.[63]. The $\chi^{2}$ test was used to test for statistical heterogeneity and the $\mathrm{I}^{2}$ statistic was used to assess the extent of variability attributable to statistical heterogeneity across trials. $\mathrm{P}>0.1$ for the $\chi^{2}$ test and $\mathrm{I}^{2}<25 \%$ were interpreted as signifying low-level heterogeneity. When there was no statistically significant heterogeneity, a pooled effect was calculated with a fixed-effects model; otherwise, a random-effects model was used.

To investigate the source of heterogeneity, predefined subgroup analyses were performed based on cancer type and assessment method. Sensitivity analyses were performed to assess the stability of the results, namely, a single study was deleted each time to reflect the influence of the individual data set on the results. Begg's funnel plots and Egger's tests were used to assess publication bias. Furthermore, we explored performed subgroup analysis on the relationship between high EZH2 expression and clinicopathological parameters in breast, lung and colorectal cancer.

Statistical analysis was performed by STATA v12.0 (Stata Corporation, TX) and Review Manager 5.0 software. All data were analyzed using the Statistical Package for Social Sciences (SPSS) software (version 16.0 for Windows). $P<0.05$ was considered statistically significant except for the Q-test.

\section{ACKNOWLEDGMENTS}

Tao Jiang and Caicun Zhou designed the study and wrote the manuscript. Fei Zhou and Guanghui Gao collected the relevant papers and data. Tao Jiang, Yan Wang and Shengxiang Ren analyzed the data. All authors reviewed the manuscript.

\section{CONFLICTS OF INTEREST}

The authors declared no conflicts of interest.

\section{GRANT SUPPORT}

This study was supported by grants from the National Natural Science Foundation of China (No. $81172101)$ and the key project of the Science and Technology Commission of Shanghai Municipality (No. 11JC1411301). 


\section{REFERENCES}

1. Tan JZ, Yan Y, Wang XX, Jiang Y, Xu HE. EZH2: biology, disease, and structure-based drug discovery. Acta Pharmacol Sin. 2014; 35:161-74.

2. Sauvageau M, Sauvageau G. Polycomb group proteins: multi-faceted regulators of somatic stem cells and cancer. Cell Stem Cell. 2010; 7:299-313.

3. Sun M, Liu XH, Lu KH, Nie FQ, Xia R, Kong R, Yang JS, Xu TP, Liu YW, Zou YF, Lu BB, Yin R, Zhang EB, et al. EZH2-mediated epigenetic suppression of long noncoding RNA SPRY4-IT1 promotes NSCLC cell proliferation and metastasis by affecting the epithelial-mesenchymal transition. Cell Death Dis. 2014; 5:e1298.

4. Geng J, Li X, Zhou Z, Wu CL, Dai M, Bai X. EZH2 promotes tumor progression via regulating VEGF-A/AKT signaling in non-small cell lung cancer. Cancer Lett. 2015; 359:275-87.

5. Ren G, Baritaki S, Marathe H, Feng J, Park S, Beach S, Bazeley PS, Beshir AB, Fenteany G, Mehra R, Daignault S, Al-Mulla F, Keller E, et al. Polycomb protein EZH2 regulates tumor invasion via the transcriptional repression of the metastasis suppressor RKIP in breast and prostate cancer. Cancer Res. 2012; 72:3091-104.

6. Knudsen ES, Dervishaj O, Kleer CG, Pajak T, Schwartz GF, Witkiewicz AK. EZH2 and ALDH1 expression in ductal carcinoma in situ: complex association with recurrence and progression to invasive breast cancer. Cell Cycle. 2013; 12:2042-50.

7. Chang CJ, Hung MC. The role of EZH2 in tumour progression. Br J Cancer. 2012; 106:243-7.

8. Zhang J, Chen L, Han L, Shi Z, Zhang J, Pu P, Kang C. EZH2 is a negative prognostic factor and exhibits prooncogenic activity in glioblastoma. Cancer Lett. 2015; 356:929-36.

9. Simon JA, Lange CA. Roles of the EZH2 histone methyltransferase in cancer epigenetics. Mutat Res. 2008; 647:21-9.

10. Li X, Gonzalez ME, Toy K, Filzen T, Merajver SD, Kleer CG. Targeted overexpression of EZH2 in the mammary gland disrupts ductal morphogenesis and causes epithelial hyperplasia. Am J Pathol. 2009; 175:1246-54.

11. Kleer CG, Cao Q, Varambally S, Shen R, Ota I, Tomlins SA, Ghosh D, Sewalt RG, Otte AP, Hayes DF, Sabel MS, Livant D, Weiss SJ, et al. EZH2 is a marker of aggressive breast cancer and promotes neoplastic transformation of breast epithelial cells. Proc Natl Acad Sci U S A. 2003; 100:11606-11.

12. Bachmann IM, Halvorsen OJ, Collett K, Stefansson IM, Straume O, Haukaas SA, Salvesen HB, Otte AP, Akslen LA. EZH2 expression is associated with high proliferation rate and aggressive tumor subgroups in cutaneous melanoma and cancers of the endometrium, prostate, and breast. J Clin Oncol. 2006; 24:268-73.
13. Hinz S, Weikert S, Magheli A, Hoffmann M, Engers R, Miller K, Kempkensteffen C. Expression profile of the polycomb group protein enhancer of Zeste homologue 2 and its prognostic relevance in renal cell carcinoma. J Urol. 2009; 182:2920-5.

14. Huqun, Ishikawa $\mathrm{R}$, Zhang J, Miyazawa H, Goto $\mathrm{Y}$, Shimizu Y, Hagiwara K, Koyama N. Enhancer of zeste homolog 2 is a novel prognostic biomarker in nonsmall cell lung cancer. Cancer. 2012; 118:1599-606.

15. He LJ, Cai MY, Xu GL, Li JJ, Weng ZJ, Xu DZ, Luo GY, Zhu SL, Xie D. Prognostic significance of overexpression of EZH2 and H3k27me3 proteins in gastric cancer. Asian Pac J Cancer Prev. 2012; 13:3173-8.

16. Cao W, Feng Z, Cui Z, Zhang C, Sun Z, Mao L, Chen W. Up-regulation of enhancer of zeste homolog 2 is associated positively with cyclin D1 overexpression and poor clinical outcome in head and neck squamous cell carcinoma. Cancer. 2012; 118:2858-71.

17. De Brot M, Rocha RM, Soares FA, Gobbi H. Prognostic impact of the cancer stem cell related markers ALDH1 and EZH2 in triple negative and basal-like breast cancers. Pathology. 2012; 44:303-12.

18. Wagener N, Macher-Goeppinger S, Pritsch M, Husing J, Hoppe-Seyler K, Schirmacher P, Pfitzenmaier J, Haferkamp A, Hoppe-Seyler F, Hohenfellner M. Enhancer of zeste homolog 2 (EZH2) expression is an independent prognostic factor in renal cell carcinoma. BMC Cancer. 2010; 10:524.

19. Ha SY, Kim SH. Co-expression of Bmil and EZH2 as an independent poor prognostic factor in esophageal squamous cell carcinoma. Pathol Res Pract. 2012; 208:462-9.

20. Cao W, Ribeiro Rde O, Liu D, Saintigny P, Xia R, Xue Y, Lin R, Mao L, Ren H. EZH2 promotes malignant behaviors via cell cycle dysregulation and its mRNA level associates with prognosis of patient with non-small cell lung cancer. PLoS One. 2012; 7:e52984.

21. Takawa M, Masuda K, Kunizaki M, Daigo Y, Takagi K, Iwai Y, Cho HS, Toyokawa G, Yamane Y, Maejima K, Field HI, Kobayashi T, Akasu T, et al. Validation of the histone methyltransferase EZH2 as a therapeutic target for various types of human cancer and as a prognostic marker. Cancer Sci. 2011; 102:1298-305.

22. Chen S, Huang L, Sun K, Wu D, Li M, Li M, Zhong B, Chen M, Zhang S. Enhancer of zeste homolog 2 as an independent prognostic marker for cancer: a meta-analysis. PLoS One. 2015; 10:e0125480.

23. Collett K, Eide GE, Arnes J, Stefansson IM, Eide J, Braaten A, Aas T, Otte AP, Akslen LA. Expression of enhancer of zeste homologue 2 is significantly associated with increased tumor cell proliferation and is a marker of aggressive breast cancer. Clin Cancer Res. 2006; 12:1168-74.

24. Pietersen AM, Horlings HM, Hauptmann M, Langerod A, Ajouaou A, Cornelissen-Steijger P, Wessels LF, Jonkers J, van de Vijver MJ, van Lohuizen M. EZH2 and BMI1 
inversely correlate with prognosis and TP53 mutation in breast cancer. Breast Cancer Res. 2008; 10:R109.

25. Athanassiadou AM, Tsipis A, Patsouris E, Gonidi M, Nicolopoulou-Stamati P, Chelidonis G, Athanassiadou P. Enhancer of zeste homologue 2 expression in breast carcinoma smears in relationship with p53, Ki-67 and other prognostic parameters. Acta Cytol. 2011; 55:180-6.

26. Gong Y, Huo L, Liu P, Sneige N, Sun X, Ueno NT, Lucci A, Buchholz TA, Valero V, Cristofanilli M. Polycomb group protein EZH2 is frequently expressed in inflammatory breast cancer and is predictive of worse clinical outcome. Cancer. 2011; 117:5476-84.

27. Reijm EA, Jansen MP, Ruigrok-Ritstier K, van Staveren IL, Look MP, van Gelder ME, Sieuwerts AM, Sleijfer S, Foekens JA, Berns EM. Decreased expression of EZH2 is associated with upregulation of ER and favorable outcome to tamoxifen in advanced breast cancer. Breast Cancer Res Treat. 2011; 125:387-94.

28. Alford SH, Toy K, Merajver SD, Kleer CG. Increased risk for distant metastasis in patients with familial early-stage breast cancer and high EZH2 expression. Breast Cancer Res Treat. 2012; 132:429-37.

29. Hussein YR, Sood AK, Bandyopadhyay S, Albashiti B, Semaan A, Nahleh Z, Roh J, Han HD, Lopez-Berestein G, Ali-Fehmi R. Clinical and biological relevance of enhancer of zeste homolog 2 in triple-negative breast cancer. Hum Pathol. 2012; 43:1638-44.

30. Jene-Sanz A, Varaljai R, Vilkova AV, Khramtsova GF, Khramtsov AI, Olopade OI, Lopez-Bigas N, Benevolenskaya EV. Expression of polycomb targets predicts breast cancer prognosis. Mol Cell Biol. 2013; 33:3951-61.

31. Panousis D, Xepapadakis G, Lagoudianakis E, Karavitis G, Salemis N, Koronakis N, Patsouris E, Koronarchis D, Grosomanidis D, Chryssikos G, Ntasiou P, Kyriakidou V, Athanassiadou AM, et al. Prognostic value of EZH2, paxillin expression and DNA ploidy of breast adenocarcinoma: correlation to pathologic predictors. J BUON. 2013; 18:879-85.

32. Roh S, Park SY, Ko HS, Sohn JS, Cha EJ. EZH2 expression in invasive lobular carcinoma of the breast. World J Surg Oncol. 2013; 11:299.

33. Bae WK, Yoo KH, Lee JS, Kim Y, Chung IJ, Park MH, Yoon JH, Furth PA, Hennighausen L. The methyltransferase EZH2 is not required for mammary cancer development, although high EZH2 and low H3K27me3 correlate with poor prognosis of ER-positive breast cancers. Mol Carcinog. 2014;

34. Dong M, Fan XJ, Chen ZH, Wang TT, Li X, Chen J, Lin Q, Wen JY, Ma XK, Wei L, Ruan DY, Lin ZX, Liu Q, et al. Aberrant expression of enhancer of zeste homologue 2, correlated with HIF-1alpha, refines relapse risk and predicts poor outcome for breast cancer. Oncol Rep. 2014; 32:1101-7.
35. Reijm EA, Timmermans AM, Look MP, Meijer-van Gelder ME, Stobbe CK, van Deurzen CH, Martens JW, Sleijfer S, Foekens JA, Berns PM, Jansen MP. High protein expression of EZH2 is related to unfavorable outcome to tamoxifen in metastatic breast cancer. Ann Oncol. 2014; 25:2185-90.

36. Kikuchi J, Kinoshita I, Shimizu Y, Kikuchi E, Konishi J, Oizumi S, Kaga K, Matsuno Y, Nishimura M, DosakaAkita H. Distinctive expression of the polycomb group proteins Bmil polycomb ring finger oncogene and enhancer of zeste homolog 2 in nonsmall cell lung cancers and their clinical and clinicopathologic significance. Cancer. 2010; 116:3015-24.

37. Lv Y, Yuan C, Xiao X, Wang X, Ji X, Yu H, Wu Z, Zhang $J$. The expression and significance of the enhancer of zeste homolog 2 in lung adenocarcinoma. Oncol Rep. 2012; 28:147-54.

38. Behrens C, Solis LM, Lin H, Yuan P, Tang X, Kadara H, Riquelme E, Galindo H, Moran CA, Kalhor N, Swisher SG, Simon GR, Stewart DJ, Lee JJ, Wistuba, II. EZH2 protein expression associates with the early pathogenesis, tumor progression, and prognosis of non-small cell lung carcinoma. Clin Cancer Res. 2013; 19:6556-65.

39. Chen X, Song N, Matsumoto K, Nanashima A, Nagayasu T, Hayashi T, Ying M, Endo D, Wu Z, Koji T. High expression of trimethylated histone $\mathrm{H} 3$ at lysine 27 predicts better prognosis in non-small cell lung cancer. Int J Oncol. 2013; 43:1467-80.

40. Wan L, Li X, Shen H, Bai X. Quantitative analysis of EZH2 expression and its correlations with lung cancer patients' clinical pathological characteristics. Clin Transl Oncol. 2013; 15:132-8.

41. Xu C, Hao K, Hu H, Sheng Z, Yan J, Wang Q, Yu L. Expression of the enhancer of zeste homolog 2 in biopsy specimen predicts chemoresistance and survival in advanced non-small cell lung cancer receiving firstline platinum-based chemotherapy. Lung Cancer. 2014; 86:268-73.

42. Mimori K, Ogawa K, Okamoto M, Sudo T, Inoue H, Mori M. Clinical significance of enhancer of zeste homolog 2 expression in colorectal cancer cases. Eur J Surg Oncol. 2005; 31:376-80.

43. Fluge O, Gravdal K, Carlsen E, Vonen B, Kjellevold K, Refsum S, Lilleng R, Eide TJ, Halvorsen TB, Tveit KM, Otte AP, Akslen LA, Dahl $\mathrm{O}$ and Norwegian Gastrointestinal Cancer G. Expression of EZH2 and $\mathrm{Ki}-67$ in colorectal cancer and associations with treatment response and prognosis. Br J Cancer. 2009; 101:1282-9.

44. Wang CG, Ye YJ, Yuan J, Liu FF, Zhang H, Wang S. EZH2 and STAT6 expression profiles are correlated with colorectal cancer stage and prognosis. World J Gastroenterol. 2010; 16:2421-7.

45. Benard A, Goossens-Beumer IJ, van Hoesel AQ, Horati H, Putter H, Zeestraten EC, van de Velde CJ, Kuppen PJ. Prognostic value of polycomb proteins EZH2, BMI1 and 
SUZ12 and histone modification H3K27me3 in colorectal cancer. PLoS One. 2014; 9:e108265.

46. Meng X, Huang Z, Wang R, Jiao Y, Li H, Xu X, Feng R, Zhu K, Jiang S, Yan H, Yu J. The prognostic role of EZH2 expression in rectal cancer patients treated with neoadjuvant chemoradiotherapy. Radiat Oncol. 2014; 9:188.

47. Liu YL, Gao X, Jiang Y, Zhang G, Sun ZC, Cui BB, Yang YM. Expression and clinicopathological significance of EED, SUZ12 and EZH2 mRNA in colorectal cancer. J Cancer Res Clin Oncol. 2015; 141:661-669.

48. Raman JD, Mongan NP, Tickoo SK, Boorjian SA, Scherr DS, Gudas LJ. Increased expression of the polycomb group gene, EZH2, in transitional cell carcinoma of the bladder. Clin Cancer Res. 2005; 11:8570-6.

49. Hinz S, Kempkensteffen C, Christoph F, Hoffmann M, Krause H, Schrader M, Schostak M, Miller K, Weikert S. Expression of the polycomb group protein EZH2 and its relation to outcome in patients with urothelial carcinoma of the bladder. J Cancer Res Clin Oncol. 2008; 134:331-6.

50. Li K, Chen MK, Situ J, Huang WT, Su ZL, He D, Gao X. Role of co-expression of c-Myc, EZH2 and p27 in prognosis of prostate cancer patients after surgery. Chin Med J (Engl). 2013; 126:82-7.

51. Liu L, Xu Z, Zhong L, Wang H, Jiang S, Long Q, Xu J, Guo J. Prognostic value of EZH2 expression and activity in renal cell carcinoma: a prospective study. PLoS One. 2013; 8:e81484.

52. Wu Z, Wang Q, Wang L, Li G, Liu H, Fan F, Li Z, Li Y, $\mathrm{Tu}$ Y. Combined aberrant expression of Bmi1 and EZH2 is predictive of poor prognosis in glioma patients. J Neurol Sci. 2013; 335:191-6.

53. He LR, Liu MZ, Li BK, Jia WH, Zhang Y, Liao YJ, Chen YC, Zhang LJ, Guan XY, Zeng YX, Kung HF, Xie D. High expression of EZH2 is associated with tumor aggressiveness and poor prognosis in patients with esophageal squamous cell carcinoma treated with definitive chemoradiotherapy. Int J Cancer. 2010; 127:138-47.

54. Liu DC, Yang ZL. Overexpression of EZH2 and loss of expression of PTEN is associated with invasion, metastasis, and poor progression of gallbladder adenocarcinoma. Pathol Res Pract. 2011; 207:472-8.
55. Lee H, Yoon SO, Jeong WY, Kim HK, Kim A, Kim BH. Immunohistochemical analysis of polycomb group protein expression in advanced gastric cancer. Hum Pathol. 2012; 43:1704-10.

56. Li Z, Wang Y, Qiu J, Li Q, Yuan C, Zhang W, Wang D, Ye J, Jiang H, Yang J, Cheng J. The polycomb group protein EZH2 is a novel therapeutic target in tongue cancer. Oncotarget. 2013; 4:2532-49. doi: 10.18632/oncotarget.1503.

57. Zhang Y, Li Y, Lin C, Ding J, Liao G, Tang B. Aberrant upregulation of 14-3-3sigma and EZH2 expression serves as an inferior prognostic biomarker for hepatocellular carcinoma. PLoS One. 2014; 9:e107251.

58. Rao ZY, Cai MY, Yang GF, He LR, Mai SJ, Hua WF, Liao YJ, Deng HX, Chen YC, Guan XY, Zeng YX, Kung HF, Xie D. EZH2 supports ovarian carcinoma cell invasion and/ or metastasis via regulation of TGF-beta1 and is a predictor of outcome in ovarian carcinoma patients. Carcinogenesis. 2010; 31:1576-83.

59. Liu Y, Liu T, Bao X, He M, Li L, Yang X. Increased EZH2 expression is associated with proliferation and progression of cervical cancer and indicates a poor prognosis. Int $\mathrm{J}$ Gynecol Pathol. 2014; 33:218-24.

60. Tan J, Yang X, Zhuang L, Jiang X, Chen W, Lee PL, Karuturi RK, Tan PB, Liu ET, Yu Q. Pharmacologic disruption of Polycomb-repressive complex 2-mediated gene repression selectively induces apoptosis in cancer cells. Genes Dev. 2007; 21:1050-63.

61. Crea F, Hurt EM, Mathews LA, Cabarcas SM, Sun L, Marquez VE, Danesi R, Farrar WL. Pharmacologic disruption of Polycomb Repressive Complex 2 inhibits tumorigenicity and tumor progression in prostate cancer. Mol Cancer. 2011; 10:40.

62. Liberati A, Altman DG, Tetzlaff J, Mulrow C, Gotzsche PC, Ioannidis JP, Clarke M, Devereaux PJ, Kleijnen J, Moher D. The PRISMA statement for reporting systematic reviews and meta-analyses of studies that evaluate health care interventions: explanation and elaboration. Ann Intern Med. 2009; 151:W65-94.

63. Tierney JF, Stewart LA, Ghersi D, Burdett S, Sydes MR. Practical methods for incorporating summary time-to-event data into meta-analysis. Trials. 2007; 8:16. 